\title{
Entre denominações geracionais: o que as narrativas acadêmicas nos ensinam sobre crianças e jovens digitais
}

\author{
Between generational denominations: what the academic narratives \\ teach us about digital children and youth \\ http://dx.doi.org/10.5007/2178-4582.2017v51n1p108
}

Sandro Faccin Bortolazzo

Universidade Federal do Rio Grande do Sul, Porto Alegre/RS, Brasil

\begin{abstract}
A partir da emergência de diversas denominações geracionais e da intensa relação de crianças e jovens com artefatos digitais (tablets, smartphones, entre outros), este artigo - inscrito sob o referencial teórico dos Estudos Culturais em Educação - tem por objetivo investigar em que contexto e sob quais condições têm sido possível a produção de crianças e jovens digitais. $\mathrm{O}$ estudo contemplou três movimentações: apresentação de um panorama sobre o conceito de geração; o mapeamento das narrativas acadêmicas; uma análise de como tais narrativas estão implicadas em produzir um tipo de geração e de educação ao estilo "digital". O aporte teórico se apoia em autores como Feixa e Leccardi, Tapscott, Prensky, Carr e Buckingham. As narrativas sinalizam os benefícios e perigos da imersão tecnológica, o que vem permeando igualmente a convocação ao uso dos aparatos tecnológicos nos espaços escolares.
\end{abstract}

Palavras-chave: geração; tecnologias digitais; crianças; jovens.
From the emergency of many generational denominations and the intense relationship of children and youth with the digital artifacts (tablets, smartphones, among others), this article - registered under the theoretical framework of Cultural Studies in Education - aims to investigate in what context and under which conditions the production of digital children and young people has been possible. The study presents three movements: an overview of the generation concept; the mapping of academic narratives; an analysis of how these narratives are implicated in producing a type of generation and a "digital" education. The theoretical referential is based on authors such as Feixa and Leccardi, Tapscott, Prensky, Carr and Buckingham. The narratives also point out the benefits and dangers of technological immersion, which has permeated the convocation for the use of technological devices in school spaces.

Keywords: generation; digital technologies; children; youth.

\section{Introdução}

É recorrente encontrar nas capas de jornais e revistas, nos programas televisivos, nas pesquisas de mercado, incontável número de expressões que indicam uma naturalização da relação entre os mais jovens e as tecnologias. Geração digital e geração Google são apenas alguns exemplos em que os adjetivos geracionais têm sublinhado a destreza de crianças e jovens em operar computadores, tablets, smartphones, para as mais diversas finalidades - entretenimento, aprendizagem, consumo, participação em redes de sociabilidade.

Inscrito no referencial teórico dos Estudos Culturais em Educação, este artigo tenta compreender e investigar em que contexto e sob quais condições têm sido possível a produção de crianças e jovens - marcados por certas 
denominações geracionais - a partir da intensa relação que mantêm com artefatos tecnológicos digitais tais como smartphones e computadores.

Esta investigação contempla três movimentos. No primeiro movimento, é apresentado um breve panorama sobre o uso e a apropriação do conceito de geração, das teorias tradicionais às contemporâneas. No segundo movimento de investigação, se dá o mapeamento de algumas narrativas, aquelas mais recorrentes, e utilizadas na literatura especializada para demarcar uma geração conectada às tecnologias. Com base nos dois movimentos anteriores, investigam-se os modos como tais narrativas estão implicadas em produzir um tipo de geração e de educação ao estilo digital, muitas vezes, amparada em argumentos de ordem determinista e polarizada.

\section{Por que geração?}

Estaria o fenômeno geracional baseado na década de nascimento em comum de uma determinada população ou vinculado a eventos completamente aleatórios e sem intervalos regulares? Seria possível tratar as gerações ao longo da história como universais, quer dizer, como entidades que configuram uma época?

Um dos significados mais aceitos é, sem dúvida, aquele que relaciona geração à idade biológica, ou seja, o período de sucessão entre descendentes em linha reta (avós, pais, filhos, e assim por diante). De acordo com Jaeger (1985), foi Auguste Comte, entre 1830 e 1840, o primeiro a desenvolver um estudo científico sobre o conceito de geração. A acepção do termo apresentada por Comte e ligada ao positivismo identificava o tempo como objetivamente mensurável. Nas palavras de Jaeger (1985, p. 275), “o progresso social só existe, de acordo com Comte, na medida em que se baseia na morte, como o renovador eterno da sociedade humana".

Na mesma direção, Feixa e Leccardi (2010) desenvolveram um trabalho sobre o conceito de geração, focado, principalmente, nas teorias da juventude. Para os pesquisadores, no entendimento de Comte, o ritmo das gerações poderia ser calculado simplesmente a partir da "medição do tempo médio necessário para que uma geração seja substituída - na vida pública - por uma nova" (COMTE apud FEIXA; LECCARDI, 2010, p. 187). Aproximadamente 30 anos era a média de tempo que se estimava para calcular a idade de formação entre uma geração e outra. Essa tem sido a noção clássica do conceito de geração, em que o progresso é visto como o resultado equilibrado entre as mudanças produzidas pela nova geração e certa estabilidade mantida pelas gerações mais antigas. 
De acordo com Moisés (2004), na Alemanha do século XVIII, ressaltase também Wilhelm Dilthey, primeiro pensador que introduziu um conceito histórico de geração. A abordagem inspirada em Dilthey é analisada por meio da conexão entre os ritmos da história e os ritmos das gerações. Para esse autor a formação de uma geração exige uma análise do tempo de experiências medido exclusivamente em termos qualitativos e "baseada em uma temporalidade concreta, constituída de acontecimentos e experiências compartilhadas" (FEIXA; LECCARDI, 2010, p.188).

Por sua vez, a atualidade do conceito em muito se deve ao pensamento de Mannheim. Para Weller (2010), Mannheim teve um duplo objetivo: distanciarse do positivismo, bem como da perspectiva histórica. Mannheim considerou o termo geração associado à própria dinâmica das transformações sociais. Por isso, segundo Mannheim (1982), as gerações podem ser consideradas resultados de muitas descontinuidades produzidas exatamente por mudanças históricas e sociais. Em outras palavras, o que o autor argumenta é que o que forma uma geração não é a data de nascimento em comum, mas o processo histórico que uma parcela da população compartilha (FEIXA; LECCARDI, 2010). Isso significa que, para Mannheim (1982), aqueles nascidos em um mesmo tempo cronológico teriam a possibilidade de presenciar acontecimentos similares, de vivenciar e processar experiências de forma semelhantes.

$\mathrm{Na}$ mesma esteira conceitual exposta por Mannheim, as contribuições de Philip Abrams oferecem outra perspectiva para pensar o conceito de geração. Para Feixa e Leccardi (2010), esse autor amplia a noção histórica e social produzida por Mannheim e relaciona o termo geração à questão identitária, entendida aqui como o resultado do entrelaçamento das histórias social e individual. "O ponto de partida de Abrams foi sua convicção de que a individualidade e a sociedade são construções históricas. Seria, portanto, necessário, analisar suas interconexões e, simultaneamente, suas mudanças ao longo do tempo" (FEIXA; LECCARDI, 2010, p. 190). Assim, seria possível falar que novas gerações criam outras identidades e que as gerações "não surgem da cadência temporal estabelecida por uma sucessão de gerações biológicas. Em outras palavras: não há padronização do tempo para medir ou prognosticar seu ritmo" (FEIXA; LECCARDI, 2010, p. 191). Uma geração pode sim ser compreendida num período de 10 anos, por exemplo, mas também cessa quando novos e grandes eventos históricos, ou melhor, quando processos econômicos e de natureza cultural tornam o sistema anterior e todas as experiências relacionadas a ele sem significado. Outra aproximação entre os conceitos de geração e identidade é aludida por June Edmunds e Bryan Turner (2002) a partir da obra Generations, Culture and Society (ainda sem tradução no Brasil). Segundo os autores, geração se refere a um grupo etário que vai 
assumindo importância social em virtude de se constituir como uma identidade cultural. Discorrendo segundo essa perspectiva, a formação das gerações pode ser pensada tanto a partir de seu caráter histórico quanto cultural e, como sugerem os autores, qualquer processo de definição geracional é atravessado por questões culturais, quer dizer, trata-se antes das formas como os membros de uma determinada geração se organizam, se constituem e se enxergam como detentores de certa identidade compartilhada. Da mesma maneira, as gerações não podem ser analisadas exclusivamente pela simples passagem do tempo. Isso porque os próprios integrantes acabam produzindo a si mesmos - com seus iguais e, presumivelmente, com os não integrantes também.

O conceito de geração, evidentemente, não está desvinculado das divisões, repetidas vezes marcadas em certas pesquisas, que se arriscam a definir crianças e jovens. Pode-se inferir que as categorias "crianças" e "jovens" são parte de uma construção em contextos sociais específicos. O conceito de juventude, por exemplo, é discutido por diversos pesquisadores brasileiros. Utiliza-se aqui de acordo com Dayrell (2003), quando afirma que a juventude não pode mais ser analisada segundo critérios rígidos, como uma etapa com fim predeterminado. Na visão de Dayrell (2003), a juventude é parte de uma condição social, mas também fruto de representação e, por isso, tem sido muito variada a maneira como cada sociedade e como cada grupo social lida com os jovens. A premissa vale igualmente para a categoria "infância" que não pode ser determinada simplesmente pela idade biológica. Para Buckingham (2007), infância não é algo que tenha um sentido fixo. "Ao contrário, a infância é variável - histórica, cultural e socialmente variável. As crianças são vistas - e veem a si mesmas - de formas muito diversas em diferentes períodos históricos, em diferentes culturas e em diferentes grupos sociais" (Idem, p.10).

\footnotetext{
Não se está querendo sugerir que os indivíduos biológicos a quem podemos coletivamente concordar em chamar de "crianças" de algum modo não existam, ou não possam ser descritos. O que se pretende é dizer que tais definições coletivas são o resultado de processos sociais e discursivos. Há nisso um certo grau de circularidade. As crianças são definidas como uma categoria particular, com características e limitações particulares, tanto por si mesmas como pelos outros - pais, professores, pesquisadores, políticos, planejadores, agências de bem-estar social e (claro) os meios de comunicação. (BUCKINGHAM, 2007, p. 10). [grifo do autor]
}

Embora muitas agências governamentais advoguem a utilização de demarcações etárias definidas, as pesquisas de caráter sociológico reclamam flexibilidade. Isso porque, além das categorias hoje serem mais elásticas e não darem conta de explicar alguns fenômenos do cotidiano, é preciso também 
levar em consideração as transformações mais recentes nas experiências dos sujeitos. A própria relação de crianças e jovens com as tecnologias digitais é um indicativo dessas outras e novas experiências. Contudo, não se está assumindo que os sujeitos a que chamamos de crianças e jovens simplesmente desapareceram, mas a ideia de infância e juventude e de todos os pensamentos, experiências e emoções vinculados a elas já não podem ser dados como estáveis.

\section{A geração digital e os nativos digitais: uma celebração às tecnologias.}

Desde meados da década de 1990, uma série de reportagens jornalísticas, pesquisas acadêmicas e também aquelas voltadas ao mercado têm procurado destacar a produtiva e intensa relação entre as crianças, os jovens e as novas tecnologias. Assim, para mapear algumas denominações acerca das crianças e dos jovens digitais, procura-se elencar aquelas mais recorrentes. No entanto, outras tantas designações poderiam ser adicionadas ou estão sendo inventadas neste momento, visto que as tecnologias digitais e a imersão das mesmas na vida em sociedade é um assunto dinâmico e vertiginoso.

Growing up digital: the rise of the net generation (no Brasil publicado em 1999 com o título Geração digital: a crescente e irreversivel ascensão da geração net), é considerado um dos estudos pioneiros na investigação a respeito das relações entre os jovens e as tecnologias. Tapscott (1999) registra algumas características desses jovens que cresceram fazendo uso dos aparatos tecnológicos e tenta prever transformações na sociedade provenientes dessa relação. $\mathrm{O}$ autor afirma que a participação da Geração digital na formação de uma cultura do século XXI por meio das tecnologias digitais corresponde a uma verdadeira revolução, cujos precedentes só podem ser comparados ao impacto da televisão na vida dos Baby Boomers ${ }^{l}$.

Qual a diferença entre a geração digital e suas antecessoras? Segundo Tapscott (1999), esta seria a primeira geração a crescer cercada pelas mídias digitais. Computadores estão nos lares, nas escolas, nos escritórios, e artefatos digitais como câmeras fotográficas, videogames e telefones celulares são lugares-comuns. $\mathrm{O}$ autor acredita que o termo geração digital (ou geração Net como é utilizado por ele também) seja a expressão mais apropriada, na medida em que reúne em um só termo o poder da demografia e da análise das

\footnotetext{
1 As pessoas que nasceram entre o final da década de 1940 e a metade dos anos 1960, segundo Tapscott (1999), estão vinculadas ao aumento dos índices de natalidade do período pós-guerra. Ao final da Segunda Guerra Mundial (1939 - 1945), o mundo presenciava o nascimento de uma geração: os chamados Baby Boomers. Nos Estados Unidos, por exemplo, a volta dos soldados para as famílias fez com que houvesse um aumento no número de mulheres grávidas e daí surgiu o termo boom, que em inglês significa, entre outras coisas, aumento rápido ou crescimento súbito. Por esta razão, a geração que aí se formou é chamada de Baby Boomers por vários pesquisadores.
} 
novas mídias. Para Tapscott (1999), a peculiaridade da geração digital está atrelada ao fato de terem nascido em meados da década de 1990 - momento econômico no qual a efervescência de parafernálias digitais passou a fazer parte do cotidiano dos jovens norte-americanos (reduto da pesquisa do autor). Tapscott parte de uma premissa que conduz toda a obra, qual seja, a do fenômeno (nunca antes experimentado pela humanidade) de ter a hierarquia do conhecimento invertida. A geração digital estaria exercendo um papel de liderança, uma vez que nem seus pais ou mesmo professores possuiriam a expertise com as tecnologias, hoje considerada central no desenvolvimento das sociedades.

Tapscott (1999) se assume um defensor da geração digital e assegura que as novas tecnologias oferecem grandes promessas para outro tipo de aprendizado. "Essa combinação de uma nova geração com novas ferramentas digitais ocasionará uma revisão na natureza da educação - tanto no contexto quanto no conteúdo" (TAPSCOTT, 1999, p. 124). A argumentação sustenta que computadores e internet seriam simplesmente precondições para um novo paradigma de aprendizado. Seguindo nesta investida, ele afirma que as abordagens tradicionais de aprendizagem são lineares, ou seja, remontam aos livros que, geralmente, devem ser lidos do início ao fim como uma ferramenta para o aprendizado. No entanto, diante do facilitado acesso da geração digital às informações via internet, essa aprendizagem não poderia mais ser encarada em termos lineares e sim considerando aspectos interativos e não sequenciais.

O mais recente livro de Tapscott sobre o tema é Grown up digital: how the net generation is changing your world (2009), no Brasil publicado em 2010 e traduzido como A hora da Geração digital - como os jovens que cresceram usando a internet estão mudando tudo, das empresas aos governos. Nele, o autor entrevistou mais de 10 mil jovens para avaliar como se dão as sociabilidades desse conjunto da população quando ingressam no universo da cultura digital. Escrito quase 10 anos depois da sua primeira obra, Tapscott (2009) assegura que, "digitalmente", o mundo em meados da década de 1990 era muito diferente do que encontramos hoje. Naquela época ainda não havia Google, Facebook, YouTube ou smartphones. Contrapondo-se a muitos estudos que acusam essa geração de superficial, carente em termos de concentração e pobre em habilidades sociais, Tapscott (2009) conclui que esses jovens, ao contrário, teriam desenvolvido novas formas de pensar, interagir, trabalhar e socializar.

A argumentação de Tapscott (2009) se baseia em dois conjuntos binários de oposições - tecnologia (internet versus televisão) e gerações (Baby Boomers versus Geração digital). Nesse debate, Buckingham (2007, p. 34) afirma que Tapscott se apoia em certo determinismo tecnológico e argumenta que 
a televisão é vista como passiva, enquanto a internet é ativa; a televisão emburrece seus usuários, enquanto a internet aguça sua inteligência; a televisão difunde uma única visão de mundo, enquanto a internet é democrática e interativa; a televisão isola, enquanto a internet cria comunidades; e assim por diante.

Tapscott é considerado um determinista tecnológico, ou seja, a tecnologia digital sempre resulta em mudanças positivas quando analisada sob a perspectiva da psicologia, da escolarização, do mundo do trabalho, da vida familiar, do mercado.

$\mathrm{Na}$ mesma vertente, outro autor, o educador e desenvolvedor de jogos eletrônicos Mark Prensky, cunhou duas expressões exploradas nos meios de comunicação e nos artigos científicos: Nativos e Imigrantes digitais. Segundo o autor, o mundo marcado pelas tecnologias digitais estaria dividido entre os Nativos e os Imigrantes digitais. A fluência com os artefatos eletrônicos, para usar uma expressão do próprio Prensky (2001), teria transformado os jovens em verdadeiros especialistas digitais, possuidores de uma capacidade múltipla, ou seja, aptos a utilizar diversas mídias ao mesmo tempo. É nesse sentido que o autor vai classificá-los como Nativos em oposição aos seus pais ou professores que nasceram antes do ingresso das tecnologias digitais na vida em sociedade e que, portanto, seriam os Imigrantes Digitais.

Prensky (2001) recorre ao termo imigrante para enfatizar que esses sujeitos estariam passando por uma espécie de "alfabetização digital" e que possuiriam um "sotaque" distinto dos nativos digitais. Para o autor, atividades cotidianas que envolvem a interação com os computadores podem comprovar tal distinção. Há inúmeros exemplos citados por Prensky (2001); os imigrantes têm o hábito de ligar para o amigo confirmando se o mesmo recebeu um e-mail, o que na ótica de um nativo seria um despropósito; os imigrantes costumam ler manuais de instrução antes de operar qualquer aparelho eletrônico, enquanto os nativos esperam que os próprios aparelhos sejam autoexplicativos.

A distinção entre nativos e imigrantes tornou-se uma espécie de alegoria comumente aceita na educação, compondo uma forma de compreender as rápidas transformações tecnológicas. A base do argumento de Prensky (2001) está em posicionar os jovens em um lugar na sociedade onde as habilidades tecnológicas têm sido amplamente reconhecidas, aceitas e celebradas, enquanto aos mais velhos caberia ocupar uma posição retrógrada, ou seja, afastada das relações com o digital. As duas categorizações trabalham no sentido de homogeneizar diversos e variados grupos de sujeitos. Contudo, tais dicotomias não contribuem para se compreender significativamente um mundo e uma sociedade tão diversos, sendo o pressuposto de homogeneidade enganoso e perigoso. De alguma forma, superestimam-se as diferenças geracionais em 
termos dos níveis de imersão tecnológica e, ao mesmo tempo, as capacidades dos sujeitos de se adaptarem aos ambientes altamente tecnológicos.

Apesar das limitações dessas duas designações, elas têm sido internalizadas por muitos professores. $\mathrm{O}$ que se percebe é que há várias suposições implícitas nessa divisão, o que tem permitido também conduzir muitas das discussões sobre os efeitos das tecnologias nos alunos e nos próprios professores. Esse tipo de binarismo certamente não coexiste pacificamente. Ele está inscrito num forte jogo hierárquico, quer dizer, um dos termos acaba sempre dominando o outro axiologicamente e fazendo com que um ocupe uma posição de "comandante". Por um lado, os professores são informados que, por conta da faixa etária em que se encontram, passariam a ter um único relacionamento com as tecnologias, concentrado exclusivamente no status de Imigrante. Por outro lado, esses mesmos professores são convidados a adaptar seus métodos de ensino e a alterar sua posição como sujeitos dentro da era digital. Os intentos, nesse caso, seriam os mesmos, quais sejam, os de consolidarem o trabalho docente, agora com vistas a alcançar e ensinar as próximas hordas de estudantes. Do mesmo modo, essas diferenças apresentam um paradoxo - o de que há uma visão profundamente essencialista dos sujeitos, sendo determinados unicamente pelo seu posicionamento geracional. Quer dizer, um Imigrante nunca poderá se tornar um Nativo ou um Imigrante nunca vai ser tão competente em operar aparelhos tecnológicos digitais quanto um Nativo.

\section{Do Google à geração superficial}

Nicholas Carr, professor do MIT (Massachusetts Institute of Technology), cria mais uma denominação para a geração que está crescendo junto ao avanço das tecnologias digitais: Geração superficial. Na obra $A$ geração superficial: $o$ que a internet está fazendo com os nossos cérebros, de 2011, o autor se dedica a investigar como as atividades cerebrais de internautas e os consequentes estímulos provocados pelo uso constante de computadores, tablets, smartphones, entre outros aparelhos e dispositivos móveis de comunicação, têm modificado em termos negativos a capacidade de concentração e as habilidades para armazenar informações. Na tentativa de contextualizar suas premissas, Carr (2011) parte das próprias experiências descritas em tom biográfico na primeira parte da obra. Assim, nas palavras do autor: "Nos últimos poucos anos tenho tido um sentimento desconfortável de que alguém, ou algo, tem estado mexendo com meu cérebro, remapeando os circuitos neurais, reprogramando minha memória" (CARR, 2011, p. 5). A tese central do autor é a de que exista um lado obscuro na internet - não o da pornografia ou dos perigos das salas de bate papo - mas algo muito mais profundo, em que 
a internet, por conta de seus inúmeros estímulos visuais, imagéticos, textuais e hiperlinks, estaria nos ensinando a parar de pensar.

Em meio a certo entusiasmo acerca das novas tecnologias, a obra - de nuance igualmente determinista, já que as tecnologias são apresentadas como vilãs destrutivas das capacidades cognitivas da memória e da concentração dos jovens - mostra o lado nocivo do debate, ou seja, chama a atenção para os inúmeros perigos do uso da internet no que diz respeito à aprendizagem. A "leitura profunda", expressão utilizada pelo autor, acabou se tornando uma verdadeira batalha. $\mathrm{O}$ pensamento profundo, contemplativo, concentrado, antes comum na vida do pesquisador, passou, então, a dar lugar a um pensar mais superficial, caótico, apressado e, de certa forma, sedento por novidades, ou melhor, ávido por estímulos sempre renovados. A narrativa oferecida por Carr (2011) endereça à internet uma capacidade de prejudicar a concentração. Ele vai alegar que, estando ou não conectado, a própria mente acabou se acostumando a receber informações do mesmo modo que elas são disponibilizadas na web, ou seja, em fluxo contínuo. E como hoje a internet é uma ferramenta tão essencial para o trabalho diário quanto para a vida social, escapar da rede é quase uma utopia. "Mesmo quando eu estava longe do meu computador, ansiava por checar meus e-mails, clicar em links, fazer uma busca no Google. Queria estar conectado" (CARR, 2011, p. 31).

Carr (2011) defende o argumento de que assim como o livro impresso mudou a forma dos homens pensarem e comunicarem, a internet estaria fazendo o mesmo. No primeiro caso, em virtude da concentração exigida para a leitura de livros, nossa sociedade teria passado por um período de certo ganho intelectual. No segundo caso, a internet, em razão da interatividade e dos múltiplos estímulos, estaria prejudicando intelectual e cognitivamente os sujeitos. Diante da dispersão causada pelos hiperlinks e pelas diversas atividades tais como a verificação de e-mails e o navegar pelas redes sociais, já não estaríamos mais capacitados à leitura de textos longos.

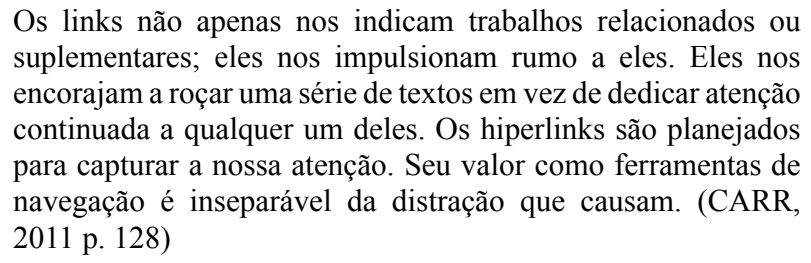

Os links não apenas nos indicam trabalhos relacionados ou suplementares; eles nos impulsionam rumo a eles. Eles nos encorajam a roçar uma série de textos em vez de dedicar atenção continuada a qualquer um deles. Os hiperlinks são planejados para capturar a nossa atenção. Seu valor como ferramentas de 2011 p. 128)

O autor declara que a internet é um ambiente de interrupções e que, ao usá-la constantemente, acabamos treinando nossas mentes para sermos interrompidos toda hora, o que acaba provocando pensamentos fragmentados. Carr (2011) discute ainda mais essa questão afirmando que não há nada 
de errado em ler superficialmente, mas que o perturbador é saber que ler apressadamente tem se tornado o hábito dominante de leitura. Há certa defesa da leitura dos livros impressos em oposição à leitura em ambientes virtuais. $\mathrm{O}$ autor expõe que não seria possível uma leitura mais complexa através da internet, isso porque quando conectamos os livros à web estamos alterando sua dinâmica, "mudamos o que ele é e também mudamos a experiência de lêlo. Um e-book não é um livro, da mesma forma que um jornal online não é um jornal" (CARR, 2011, p. 146).

Além da geração superficial, há também a Google Generation ou Geração Google em português, nome conferido pelo pesquisador da University College de Londres, Ian Rowlands. O termo ganhou destaque a partir da pesquisa intitulada Comportamento Informativo do Pesquisador do Futuro, liderada por Rowlands em 2008 e que teve o intuito de investigar o impacto da era digital na vida dos jovens quando em busca de informações na internet. O autor sugeriu o período do início dos anos 1990, uma vez que esses jovens, na atualidade, estariam entrando ou mesmo saindo das universidades, e formariam a primeira geração que nasceu fazendo uso da internet nas pesquisas escolares. A expressão Geração Google entrou em uso como uma forma abreviada para se referir a um grupo cujo primeiro arranque para o conhecimento se dá por meio da internet e, principalmente, através das páginas indexadas no site de pesquisa Google. O autor utiliza o termo Google Generation em contraste às gerações que buscavam conhecimento em outros lugares como nas bibliotecas. Segundo os apontamentos do autor, o impacto das tecnologias na vida dos sujeitos da Geração Google tem sido superestimado pelos pesquisadores. Mesmo que esses jovens apresentem destreza para operar com familiaridade computadores, eles acabam confiando demasiadamente nas ferramentas tecnológicas. A Geração Google é mais talentosa do que outras gerações quando se trata de procurar informações, assegura o autor. No entanto, para Rowlands (2008), estratégias como copiar e colar textos não podem ser percebidas como habilidades que os posicionem em vantagem sobre outros sujeitos. Para a Geração Google é melhor "ver do que ler e eles não possuem a habilidade crítica analítica necessária para avaliar as informações que encontram na web" (ROWLANDS, 2008, p. 138). Por isso, na visão do autor, a presença ubíqua das tecnologias na vida de crianças e jovens ainda não resultou em melhor desempenho escolar.

Entre os resultados apresentados por Rowlands (2008), confirma-se que essa é uma geração dos cliques, sem paciência, ansiosa para pular etapas. Uma geração ao estilo quick and easy (rápida e fácil). $\mathrm{O}$ autor atesta também que o uso que essas crianças e jovens fazem da internet é superficial, promíscuo e rápido, em que respostas com pouca credibilidade são fornecidas e que, 
infelizmente, acabam prevalecendo. Eles utilizam o Google porque é mais conveniente, conclui o autor. Rowlands (2008) inclusive comenta aspectos a respeito dos próprios professores que, supostamente, teriam outros meios mais sofisticados para buscar e analisar informações, mas como o Google torna a pesquisa mais rápida e conveniente, acabam confirmando as mesmas tendências que seus alunos.

Outras nomenclaturas poderiam fazer parte do corpo deste artigo como Geração Z, Homo Zappiens (VEEN; VRAKKING, 2009), iGeneration (ROSEN, 2010), entre outras. No entanto, o intuito foi mostrar o debate polarizado, concentrando-se de um lado os argumentos de que as tecnologias digitais estariam comprometendo o desenvolvimento social e intelectual de crianças e jovens, e do outro lado os argumentos cada vez mais disseminados de que as tecnologias poderiam oferecer novas liberdades, autonomia e aumento das capacidades cognitivas.

\section{A produção de crianças e jovens para uma educação ao estilo digital}

Há muitas denominações para se referir a uma geração imersa no universo digital. Todavia, isso não quer dizer simplesmente que um vocabulário todo novo surgiu para falar de uma determinada geração, mas que, neste sentido, uma nova importância foi dada às tecnologias digitais - em casa, no trabalho, nos espaços de entretenimento e lazer, nas escolas e universidades. Seguindo Miller e Rose (2012), esses novos vocabulários não são tão importantes devido ao significado que produzem, mas sim porque operam como "maneiras de tornar a existência pensável e factível" (idem, p.68). Ou seja, cada vez mais expressões como geração digital ou nativos digitais entram em circulação nos meios jornalísticos, acadêmicos, instaurando condições para que se possa pensar a constituição de uma geração atrelada ao digital. A importância dessas denominações não é simplesmente uma mera justificativa. É preciso considerálas como constitutivas de saberes que pretendem, segundo Rose (1998), produzir conhecimento sobre os sujeitos e instituir modos de ser sujeito.

Narrar crianças e jovens como imersos em um estilo de vida completamente cercado pelas tecnologias sublinha o tom celebratório, polarizado e inédito conferido a essa geração. De um lado se dispõe toda uma argumentação alarmista sobre o impacto das tecnologias - alegações que têm atribuído às tecnologias certo poder em prejudicar o desenvolvimento moral, cognitivo ou mesmo social. Do outro lado estão dispostos os "defensores" - utilizando argumentos de ordem igualmente determinista - ao sugerir que a relação com as tecnologias tem proporcionado novas formas de aprendizagem, aumento do Q. I. (quociente de inteligência), entre outros benefícios. 
O otimismo de certos rótulos acadêmicos, a exemplo dos nativos digitais (PRESNKY, 2001), da geração digital (TAPSCOTT, 1999; 2009) são, até certo ponto, atraentes. Isso porque essas narrativas apresentam um apelo emocional forte, garantindo aos mais jovens qualidades análogas a "gênios" e que qualquer pai ou mãe se orgulharia de ter em casa. Mesmo assim, toda essa positividade tem sido contestada por outros especialistas como Carr (geração superficial, 2011) e Rowlands (Geração Google, 2009). Ao contrário das posições otimistas, eles vão alertar que por serem ávidos por tecnologias, aliás, essa é uma representação incontestável, essas crianças e jovens estariam cada vez mais desatentos, desorientados, alienados e inaptos a prestar atenção ou fazer apenas uma única atividade de cada vez.

Um dos gurus das tecnologias na década de 1980, o americano Seymour Papert (1980), dizia que os computadores transformariam a educação e tornariam o processo educativo praticamente redundante. Segundo o autor, os computadores iriam proporcionar aos sujeitos o poder de determinar seus próprios padrões de educação. Para Buckingham (2010), Papert foi ainda mais radical ao afirmar que no futuro não existiriam mais escolas.

Ele não estava sozinho. Steve Jobs, o fundador da Apple
Computers, então preparando o caminho para alcançar
o mercado educacional americano, era outro defensor
apaixonado do potencial revolucionário da computação
educacional; eles mais tarde juntaram-se a uma coorte
entusiástica de marqueteiros visionários, como Bill Gates, da
Microsoft, ávidos por usar as escolas como trampolins para
um mercado doméstico muito mais valioso. (BUCKINGHAM,
2010, p. 38). [grifo do autor]

Para o bem ou para o mal, "a escola enquanto instituição ainda está firme entre nós e a maior parte do ensino e aprendizado que aí se dá manteve-se quase intocável apesar da influência da tecnologia" (BUCKINGHAM, 2010, p. 38). Mesmo diante da argumentação, hoje é visível que tablets, computadores e internet têm se tornado elementos significativos na vida de crianças e jovens. A primeira relação das crianças com as tecnologias já não ocorre no contexto escolar. Elas ingressam nos espaços escolares, muitas vezes, previamente munidas do conhecimento e das habilidades tecnológicas. Assim, ao mesmo tempo em que se atribuem às tecnologias digitais grande potencial como ferramenta pedagógica, se sustenta que seus usos na educação não estariam estimulando a imaginação e a inteligência dos jovens. Ambas as perspectivas têm sido cada vez mais presentes nos estudos sobre alfabetização, aprendizagem, ensino, etc. 
Os argumentos sobre a presença das tecnologias digitais nos espaços escolares se baseiam, de maneira geral, em oposições deterministas, em que as tecnologias são vistas como autônomas em relação a outras forças que atuam na sociedade e independentes de quaisquer contextos. Nos primórdios da televisão, o debate contrastante era recorrente. A televisão foi inicialmente promovida entre pais e professores como um meio educacional. Segundo Buckingham (2007), a televisão era vista como a materialização do futuro da educação. "Elas eram descritas como máquinas de ensinar que iriam trazer novas experiências e novas formas de aprender do mundo exterior para dentro da sala de aula" (idem, p. 31). Mesmo naquela época, as esperanças utópicas eram contrabalançadas pelos receios de que a televisão pudesse substituir os professores. O meio de comunicação "foi celebrado como uma forma de nutrir o desenvolvimento emocional e educacional das crianças e, ao mesmo tempo, condenado por afastá-las das atividades mais saudáveis e valiosas" (idem, p. 31).

Nas narrativas acadêmicas de uma vertente mais positiva, há uma abordagem das novas tecnologias como recursos pedagógicos produtivos e, nesse sentido, observa-se uma marca imperativa associando as tecnologias a "uma educação melhor", "uma educação digital", "uma educação do e para o futuro". A inserção das novas tecnologias nos ambientes escolares, além de constituir um discurso próprio, nos últimos anos, tem materializado ou sugestionado a inclusão dos alunos e das escolas na lógica das redes, estendendo os benefícios de uma educação ao estilo digital.

Hoje, é possível notar certo condicionamento das práticas pedagógicas para que os recursos digitais sejam inseridos e utilizados nas salas de aula. Essas práticas vão sendo operacionalizadas quando as escolas instituem os laboratórios de informática, disponibilizam lousas digitais, ou mesmo quando a medicina traz evidências de que o raciocínio dos jovens melhora com o uso das tecnologias. O movimento de entrada dos aparatos tecnológicos na educação tem produzido, inclusive, políticas públicas, como no caso da distribuição pelo Ministério da Educação em 2012 de tablets para professores da rede pública de ensino. Suponho junto com Buckingham (2010, p. 41) que boa parte dos planos de ação são igualmente caracterizado por uma forma de determinismo tecnológico - a noção de que "a tecnologia digital automaticamente produzirá certos efeitos (por exemplo, em relação aos modos de aprendizagem ou a determinadas formas de cognição) sem restrição dos contextos sociais em que seja usada, nem mesmo dos atores sociais que a usem".

Vale ressaltar ainda que a maioria das experiências que crianças e jovens mantêm com as tecnologias, segundo as narrativas, se dão para além dos muros escolares. O divisor, agora associado às tecnologias digitais, pode ser 
visto como produtor de um abismo entre o mundo de crianças e jovens fora dos ambientes escolares e as ênfases dos tradicionais sistemas educacionais. Quer dizer, quando se comenta que a instituição "Escola" está em crise, que existe um descompasso entre professores e alunos, certamente o envolvimento dos jovens com as tecnologias surge como alvo assertivo. No entanto, a ideia de que a tecnologia por si transformaria a educação é uma ilusão. A educação escolarizada provavelmente continue servindo a muitas funções - econômicas, sociais, políticas - que não se limitam ao seu papel exclusivamente de ensino.

Contudo, é preciso compreender que o que a revolução tecnológica introduz nas escolas não é apenas uma quantidade inusitada de máquinas eletrônicas e móveis, mas relações entre processos simbólicos e culturais. Assim, permanecer à margem das mudanças seria um tanto quanto ingênuo e ignorar o fato de que o mundo é editado constantemente, ou seja, é redesenhado num trajeto entre milhares de mediações - sejam elas advindas do rádio, da televisão, da internet, das revistas e dos jornais, da escola - também.

O que se pode depreender desse debate é que, talvez, os interesses estejam mudando rapidamente e constantemente e, por isso, certo estilo de vida de crianças e jovens contemporâneos tem sido representado como algo incompatível com os sistemas formais de educação. Além disso, em meio às narrativas acadêmicas, as crianças e os jovens digitais acabaram sendo narrados como um "grupo" complexo, no qual é preciso intervir, instruir e orientar. Os saberes especializados sempre têm algo a dizer sobre os fenômenos emergentes. Em outras palavras, segundo Rose (1998), esses saberes atuariam narrativamente inventando e produzindo essa geração. Os saberes especializados mais do que apenas identificar os comportamentos e atributos dos sujeitos digitais, invariavelmente, eles fornecem uma série de orientações para as condutas de pais, professores e dos próprios jovens.

\section{Referências}

BUCKINGHAM, D. Crescer na Era das mídias eletrônicas. Tradução Gilka Girardello e Isabel Orofino. Rio de Janeiro: Loyola, 2007.

BUCKINGHAM, D. Cultura digital, educação midiática e o lugar da escolarização. Educação \& Realidade, Porto Alegre, v. 35, n. 3, set./dez. 2010.

CARR, N. A geração superficial: o que a internet está fazendo com os nossos cérebros. Rio de Janeiro: Agir, 2011.

DAYRELL, J. O jovem como sujeito social. Revista Brasileira de Educação, Rio de Janeiro, n. 24, p. 40-53, dez. 2003. 
EDMUNDS, J.; TURNER, B. S. Generations, culture and society. Philadelphia: Open University Press, 2002.

FEIXA, C.; LECCARDI, C. O conceito de geração nas teorias sobre a juventude. Sociedade \& Estado, Brasília, v. 25, n. 2, maio/ago. 2010.

JAEGER, H. Generations in History: Reflections on a Controversial Concept. History and Theory, Santa Barbara, v. 24, n. 3, p. 273-292, 1985.

MANNHEIM, K. O problema sociológico das gerações. Tradução Cláudio Marcondes. In: M. M. Foracchi (Org.). Karl Mannheim: Sociologia, São Paulo: Ática, 1982, p. 67-95.

MILLER, P.; ROSE, N. Governando o presente. São Paulo: Paulus, 2012.

MOISÉS, M. Dicionário de termos literários. 1. ed. rev. e ampl. São Paulo: Cultrix, 2004.

PAPERT, S. Mindstorms: children, computers and powerful ideas. New York: Basic Books, 1980.

PRENSKY, M. Digital natives, digital immigrants, part I. On the Horizon, Lincoln, v. 9, n. 5, p. 1-6, 2001.

ROSE, N. Governando a alma: a formação do eu privado. In: SILVA, T. T. (Org.) Liberdades Reguladas. Petrópolis: Vozes, 1998, p. 30-45.

ROSEN, L. D. Rewired: Understanding the iGeneration and the Way They Learn. New York: Palgrave Macmillan, 2010.

ROWLAND, I. The Google Generation: are ICT Innovations Changing Information Seeking Behavious. Oxford: Chandos, 2009.

TAPSCOTT, D. Growing up digital: the rise of net generation. New York: McGraw-Hill, 1998.

TAPSCOTT, D. Grown up digital: how the net generation is changing your world. New York: McGraw-Hill, 2009.

VEEN, W.; VRAKKING, B. Homo zappiens: educando na era digital. Porto Alegre: Artmed, 2009.

WELLER, W. A atualidade do conceito de gerações de Karl Mannheim. Dossiê: a atualidade do conceito de gerações na pesquisa sociológica. Sociedade e Estado, Brasília, v. 25, n. 2, p. 205- 224, maio/ago. 2010. 
Submissão em: 16/10/2016

Revisão em: 30/12/2016

Aceite em: 21/05/2017

Sandro Faccin Bortolazzo é doutor em Educação pela Universidade Federal do Rio Grande do Sul - UFRGS. Bacharel em Comunicação Social/Jornalismo pela PUCRS. Mestre em Educação pela ULBRA - linha de pesquisa Estudos Culturais em Educação. Doutor em Educação pela UFRGS na mesma linha de pesquisa. Interesses de pesquisa abrangem novas tecnologias de informação e comunicação, geração digital, cultura digital, juventude e consumo. É integrante do Núcleo de Estudos sobre Currículo, Cultura e Sociedade (NECCSO) da UFRGS. Atua na gestão de clientes da América do Norte e Latina na empresa alemã SAP, focada no ramo de tecnologia da informação.

Endereço: Núcleo de Estudos sobre Currículo, Cultura e Sociedade - NECCSO/ UFRGS. Av. Paulo Gama - Prédio 12201 - Sala 700-09. Porto Alegre /RS, Brasil.

CEP 90040-060

E-mail: sandrobortolazzo@hotmail.com 